\title{
Ethionamide Alters Thyroid Receptor Gene Expression in Rats' Muscle
}

\author{
Ronny Lesmana ${ }^{1,2, *}$, Setiawan ${ }^{3}$, Ferdyan Efza $^{4}$, Yuni Susanti Pratiwi ${ }^{1,2}$, Gilang Muhamad Nur Iqbal ${ }^{2}$, \\ Hanna Goenawan ${ }^{1,2}$, Nova Sylviana ${ }^{1,2}$, Unang Supratman ${ }^{5}$ \\ ${ }^{1}$ Department of Biomedical Sciences, Faculty of Medicine, Universitas Padjadjaran, Jl. Raya Bandung Sumedang No.KM 21, \\ Jatinangor 45363, Indonesia \\ ${ }^{2}$ Department of Physiology, Molecular Laboratory, Central Laboratory, Universitas Padjadjaran, Jl. Raya Bandung Sumedang No.KM 21, \\ Jatinangor 45363, Indonesia \\ ${ }^{3}$ Department of Basic Medical Sciences, Faculty of Medicine, Universitas Padjadjaran, Jl. Raya Bandung Sumedang No.KM 21, \\ Jatinangor 45363, Indonesia \\ ${ }^{4}$ Undergraduate Program of Medical Doctor, Faculty of Medicine, Universitas Padjadjaran, J1. Raya Bandung Sumedang No.KM 21, \\ Jatinangor 45363, Indonesia \\ ${ }^{5}$ Department of Chemistry, Faculty of Mathematics and Natural Sciences, Universitas Padjadjaran, J1. Raya Bandung Sumedang No.KM 21, \\ Jatinangor 45363, Indonesia \\ *Corresponding author. E-mail: ronnylesmana18@gmail.com
}

\section{Abstract}

$\mathrm{B}$

ACKGROUND: Ethionamide usage as one of the drug regimens still becomes a challenge due to high numbers of patients developing hypothyroid. Ethionamide had been associated with the inhibition of thyroid hormone (TH) synthesis and interestingly, ethionamide $\left(\mathrm{C}_{8} \mathrm{H}_{10} \mathrm{~N}_{2} \mathrm{~S}\right)$-induced hypothyroidism is supported by its similar structure with thioamides, propythiouracil $\left(\mathrm{C}_{7} \mathrm{H}_{8} \mathrm{~N}_{2} \mathrm{~S}\right)$. However, hypothyroidism is not solely caused by its production, it could be caused by signaling alteration. Therefore, knowing that important $\mathrm{TH}$ action is determined via genomic pathway, alteration of this receptor could bring serious clinical problem. Unfortunately, there is limited study about the regulation of ethionamide and its connection on $\mathrm{TH}$ genomic signaling especially thyroid hormone receptor (TR) gene expression in soleus, gastrocnemius and cardiac muscle.

METHODS: Thirty-eight rats were divided into control, ethionamide and propylthiouracyl groups. After 12-week treatment, rat were sacrificed, then gastrocnemius, soleus and cardiac muscles were dissected out, snap freezed using liquid nitrogen, and stored in $-80^{\circ} \mathrm{C}$ until use. RNA was extracted and run for reverse transcription polymerase chain reaction (RT-PCR).

RESULTS: In soleus muscle, ethionamide stimulated TR mRNA expressions and deiodinase compared to control group. In contrast, TR 1 gene expression was not affected by ethionamide administration. In gastrocnemius muscle, only TR $\beta 1$ gene and Dio2 gene expressions that were significantly increased compared to control group. In cardiac muscle, ethionamide significantly stimulated all the thyroid hormone receptor isoform and iodothyronine deiodinase gene expression compared to the control group.

CONCLUSION: Long ethionamide treatment upregulates TR gene expressions and deiodinase in soleus and cardiac muscle, there is different expression pattern of soleus, gastrocnemius and cardiac muscle after ethionamide stimulation.

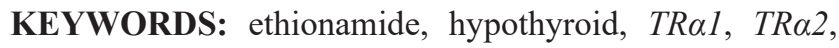
TR $\beta 1, T R \beta 2$

Indones Biomed J. 2020; 12(3): 220-6 


\section{Introduction}

Ethionamide $\left(\mathrm{C}_{8} \mathrm{H}_{10} \mathrm{~N}_{2} \mathrm{~S}\right)$ is bacteriostatic anti-tuberculosis agent which derives from isonicotinic acid and act as oral second line drugs treatment regimen for multi drug resistance tuberculosis (MDR-TB).(1) Ethionamide are pro drugs that require enzymatic activation by mycobacterial EthA and convert ethionamide into InhA competitive inhibitor of Mycobacterium tuberculosismycolic acid synthesis.(2) The most frequently observed side effects of ethionamide include gastrointestinal disturbance, psychiatric disorder, arthralgia, hepatitis, peripheral neuropathy, epileptic seizures, dermatological effects, ototoxicity, nephrotoxicity and hypothyroidism.(3)

Hypothyroidism is a known complication of MDR-TB treatment, which using ethionamide as on of its regimen. $(4,5)$ Interestingly, $28-49 \%$ of patients have developed hypothyroidism during MDR-TB treatment, which may indicate the importance of understanding the complete mechanism.(6) Studies revealed that ethionamide have direct effect to thyroid hormone (TH) synthesis, which induced hypothyroidism.(7) Aside from alteration of TH synthesis, the molecular mechanism of ethionamide effects on regulating thyroid hormone receptor (TR) gene expression remains unclear.

$\mathrm{TH}$ is essential for the regulation of metabolic processes throughout the body, which deficiency of this hormone alter normal body function.(8) TH synthesis in thyroid gland is regulated by the level of thyroid stimulating hormone (TSH) and thyrotropin releasing hormone (TRH). TSH and TRH level are regulated by the level of thyroxine (T4) and triiodothyronine (T3) via binding to TSH- $\beta 2$ and TRH- $\beta 2$ receptor. TH form in the serum are $\mathrm{T} 3$ and $\mathrm{T} 4$ form, $\mathrm{T} 3$ is active form of $\mathrm{TH}$ and $\mathrm{T} 4$ needs to be converted to T3 form by deiodinase enzyme activity in tissues. Deiodenase act as enzyme for activating or deactivating. Iodothyronine deiodinase (Dio) 1 and Dio2 are activating enzyme which catalyze conversion of T4 into T3 in circulation, and Dio3 act as deactivating enzyme which catalyze conversion of T4 into reverse T3 (rT3) and the conversion of T3 to $\mathrm{T} 2$. TH action in molecular level works in genomic and nongenomic pathway, which $\mathrm{T} 3$ and $\mathrm{T} 4$ serum level, and $\mathrm{TH}$ receptor mechanism are essential for normal cells function throughout the body. There are 2 TR genes, namely $T R \alpha$ and $T R \beta .(9,10) T R \alpha 1$ is mostly expressed in cardiac muscle, skeletal muscle, and central nervous system. TR $\beta 1$ is highly expressed in the liver and kidney, while TR $\beta 2$ is highly expressed in retina, and cochlea.(11)
Unfortunately, there is limited study about ethionamide effects on TR gene expression. Thus, exploring the effects of ethionamide on TR gene expression might be beneficial in the development of a new ethionamide post effect treatment which induce hypothyoid.

\section{Methods}

\section{Animal Model and Treatment}

All animal procedure is approved by Ethical Committee of Faculty of Medicine, Universitas Padjadjaran (No. 1462/ UN6.KEP/EC/2019). Thirty-eight, male, wistar rats, aged 20 weeks old, were bred in PT. Bio Farma, Bandung, Indonesia. Rats were kept in comfort room at $24^{\circ} \mathrm{C}$ temperature, $68 \%$ humidity. Rats were given food and water ad libitum for 12 weeks per day in the Animal Laboratory, Faculty of Medicine, Universitas Padjadjaran.

Rats were divided into 3 groups, which were negative control group (no treatment), treatment group (ethionamide treatment), and positive control group (propylthiouracyl treatment). Each group were given its respective treatment for 12 weeks. Ethionamide (CAS Number: 536-33-4; E6005, Sigma, North Liberty, USA) was diluted in water accordingly and specific rat dose were counted (1.66 $\mathrm{mg} / 200$ gram body weight) and given orally by using soft gavage for 12 weeks consecutively. We used isoflurane anaesthesia 1-3\% inhalant during sacrifice. Gastrocnemius, soleus, and cardiac muscle were removed, dip frozen into liquid nitrogen and stored in $-80^{\circ} \mathrm{C}$ until use.

\section{Reverse Transcription Polymerase Chain Reaction (RT- PCR) Examination}

Soleus, gastrocnemius, and cardiac muscle tissue were collected, weighted for $25 \mathrm{mg}$ into microtube and used for RNA isolation using TRIsure reagent (Invitrogen, Carlsbad, California, USA). Total RNA were quantified using Multimode Microplate Reader at 268/280 nm absorbance spectrophotometry (Tecan, Männedorf, Switzerland). Specific primer were used in this study for TR $\alpha 1, T R \alpha 2$, TRß1, TRß2, Dio1, Dio2, Dio3 and GAPDH as internal controls for normalization (Table 1). Primers were purchased from Sigma (Genetika Science, Singapore) and Onestep RT-PCR Kit by Bioline (London, UK). Twentyfive $\mu \mathrm{L}$ reaction mixture contained $10 \mathrm{x}$ reaction buffer, $200 \mu \mathrm{M}$ deoxynucleoside triphosphates (dNTPs), $1 \mu \mathrm{L}$ of each oligonucleotide primer at $20 \mathrm{mM}(0.8 \mathrm{mM}$ each primer), and $300 \mathrm{ng}$ of RNA and 1 unit of Taq polymerase enzyme. All samples were amplified with a Thermal 
Table 1. Specific primers used in this study.

\begin{tabular}{|c|c|c|c|c|}
\hline Gene & Primer Sequence & Product Size (bp) & $\operatorname{Tm}(\mathbf{C})$ & Cycle \\
\hline \multirow{2}{*}{ TRa1 } & F 5'-TGAGCACTACGTCAACCACC-3' & \multirow{2}{*}{136} & \multirow{2}{*}{590} & \multirow{2}{*}{29} \\
\hline & R 5'-GGTGGGGCACTCGACTTTC -3' & & & \\
\hline \multirow{2}{*}{$T R \alpha 2$} & F 5'-ATGTTTTCTCCTCTGGCTGTCC-3' & \multirow{2}{*}{265} & \multirow{2}{*}{570} & \multirow{2}{*}{29} \\
\hline & R 5'-TGGGGCACTCGACTTTCAT-3' & & & \\
\hline \multirow{2}{*}{$T R \beta 1$} & F 5'-ACTCGGTATCAAGCCTGCTC-3' & \multirow{2}{*}{284} & \multirow{2}{*}{590} & \multirow{2}{*}{29} \\
\hline & R 5'-TCACATGTGGCAATTACAGCG-3' & & & \\
\hline \multirow{2}{*}{ TRB2 } & F 5’-ACTGATGGCTCTTTGTCCCG-3' & \multirow{2}{*}{183} & \multirow{2}{*}{590} & \multirow{2}{*}{29} \\
\hline & R 5'-GAACGCGGCTCCATTGAAAC-3' & & & \\
\hline \multirow{2}{*}{ Dio1 } & F 5'- TCCTTCTGTCCCTACGGGATG-3' & \multirow{2}{*}{197} & \multirow{2}{*}{600} & \multirow{2}{*}{31} \\
\hline & R 5'- GCCCACCTTATGAGCTACAGT-3' & & & \\
\hline \multirow{2}{*}{ Dio 2} & F 5'-TACCTGCTTCAGGATTGGACAC -3' & \multirow{2}{*}{123} & \multirow{2}{*}{600} & \multirow{2}{*}{30} \\
\hline & R 5'-TGCAGCAGCAGTATGTTTGTG -3' & & & \\
\hline \multirow{2}{*}{ Dio3 } & F 5'-TTCCCCGCCTAGCTTTAGGT-3' & \multirow{2}{*}{144} & \multirow{2}{*}{600} & \multirow{2}{*}{31} \\
\hline & R 5'-GGAACCCAGAGCACTTTCCC-3' & & & \\
\hline \multirow{2}{*}{ GAPDH } & F 5'-CCCATTCTCAGCCTTGACTGT-3' & \multirow{2}{*}{177} & \multirow{2}{*}{590} & \multirow{2}{*}{24} \\
\hline & R 5'-TCTTGCCTCAGATTTGGCCG-3' & & & \\
\hline
\end{tabular}

Cycler following PCR protocol repeated for 31 cycle; final elongation at $72^{\circ} \mathrm{C}$ for $7 \mathrm{~min}$; then cooling to $4^{\circ} \mathrm{C}$.

Five $\mu \mathrm{L}$ of PCR products were combine with run on a $1.2 \%$ agarose gel TAE, stained with green dye. Electrophoresis HU10 SCIE-PLAS from Scie-Plas Ltd. (Cambridge, United Kingdom) were used in this research. Gel was visualized using blue pad and density of PCR band products in the photograph were analized using Image $\mathrm{J}$ software (NIH, Bethesda, USA).

\section{Statistical Analysis}

All data were analysed using Graphpad Prism software version 7.00 for windows (GraphPad Software, San Diego, USA). Results were tested with One Way ANOVA test, Kruskal Wallis and followed by Mann Whitney or Tukey post hoc test with $95 \%$ confidence interval $(p<0.05)$.

\section{Results}

Figure 1 showed the electrophoresis image of TR $\alpha 1, T R \alpha 2$, TRß1, TR $\beta 2$, Dio1, Dio2, Dio3 mRNA expression in soleus, gastronemius and cardiac muscle. In soleus muscle, TR mRNA expressions were upregulated by ethionamide treatment. $T R \alpha 2$ gene expression was increased 1.3 fold compared to the control group. Similarly, $T R \beta 1$ and $T R \beta 2$ were increased 1.6 fold and 1.4 fold compared to the control group. In contrast, TR 1 gene expression was not affected by ethionamide administration. Further, we analyze the effect of ethionamide treatment on iodothyronine deiodinase. Iodothyronine deiodenase was also upregulated by ethionamide treatment; Dio 1 is increased 1.2 fold, Dio 2 is increased 1.2 fold, and Dio3 is increased 1.2 fold compared to the control group (Figure 2).

In gastrocnemius muscle, there is a different pattern of expression. The TR and iodothyronine deiodinase expression compared to pattern in soleus group. Only $T R \beta 1$ gene (1.22 folds) and Dio2 (1.5 folds) gene expressions were significantly increased than control group $(p<0.05)$. However, TR $\alpha 1, T R \alpha 2$, Dio1, Dio3 gene expressions were not been changed (Figure 3).

In the cardiac muscle, ethionamide stimulates significantly the TR gene expression, TR $\alpha 1$ by 2.3 folds, $T R \alpha 2$ by 3.7 folds, $T R \beta 1$ by 4 folds, TR $\beta 2$ by 3.2 folds, and also iodothyronine deiodinase gene expression, Diol by 3.6 folds, Dio 2 by 2,8 folds, Dio 3 by 2.15 fols compared to the control group (Figure 4).

\section{Discussion}

Physiological changes are due to ethionamide share similar structure with thioamides, for example, propythiouracil $\left(\mathrm{C}_{7} \mathrm{H}_{8} \mathrm{~N}_{2} \mathrm{~S}\right)$ and methimazole $\left(\mathrm{C}_{4} \mathrm{H}_{6} \mathrm{~N}_{2} \mathrm{~S}\right)$. Its similar structure induce inhibition of peroxidase enzyme which decrease the iodine conversion to iodide, and inhibit organification of 


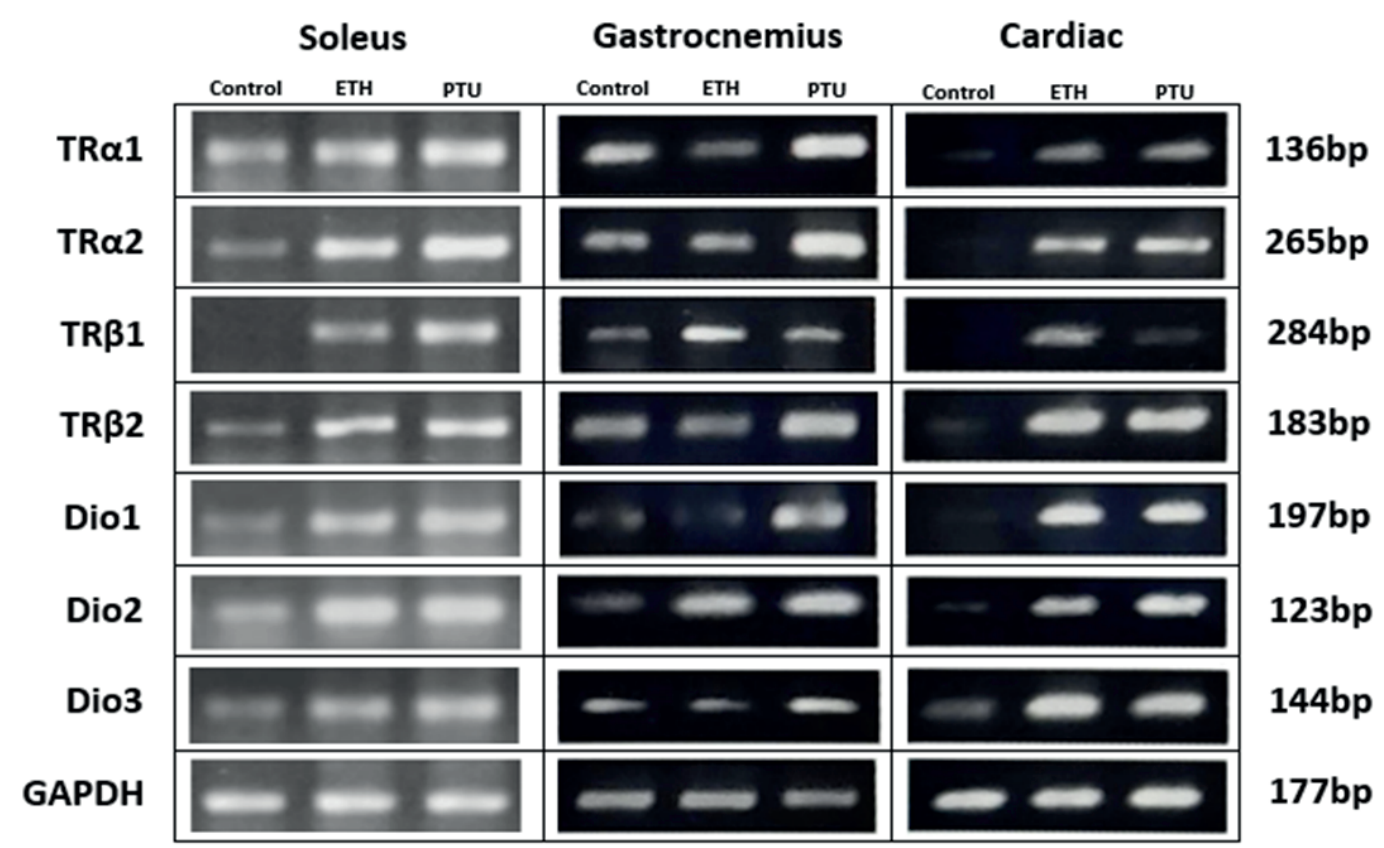

Figure. 1. Representative electrophoresis image of thyroid hormone receptor (TR $\alpha 1, T R \alpha 2, T R \beta 1$ and $T R \beta 2)$ and iodothyronine deiodinase (Dio1, Dio2, Dio3) mRNA expression in soleus, gastronemius and cardiac muscle.

iodide into monoiodothyronine (MIT) and diiodothyronine (DIT), which reduce TH synthesis. $(5,12)$ This inhibition mechanism induce lower T3 and T4 in circulation.

In this present study, ethionamide upregulates significantly in TR and iodothyronine deiodenase gene expression on soleus and cardiac muscle, however this effect seem does not affect it in gastrocnemius muscle tissue (Figure 1). Our data showed that 12 weeks of ethionamide treatment altered the gene expression and might affect the genetic modulation of TH via TR. TH action works in genomic and nongenomic pathway. In genomic pathway, TR works with thyroid hormone response element (TRE), heterodimeric partner, coregulator, and deiodenase to regulate RNA transcription in TR-DNA complexes. TRE are transcription factors that bind to TR and TH-regulated genes. $(13,14)$ Heterodimeric partner, like retinoid $\mathrm{X}$ receptor, peroxisome proliferator-activated receptor, and vitamin D receptor increase TR to TRE binding. $(15,16)$ Coregulator regulate TR-DNA complexes transcription by two mechanism, corepressor and coactivator. Corepressors, consist of silencing mediator of retinoid and thyroid hormone receptor (SMRT) and nuclear receptor corepressor (NCoR), repress transcription by binding with TR-DNA complexes. In the presence of ligand, coactivators consist of steroid receptor, Trip-1, and TR-associated protein coactivator complex will replace corepressor in TR-DNA

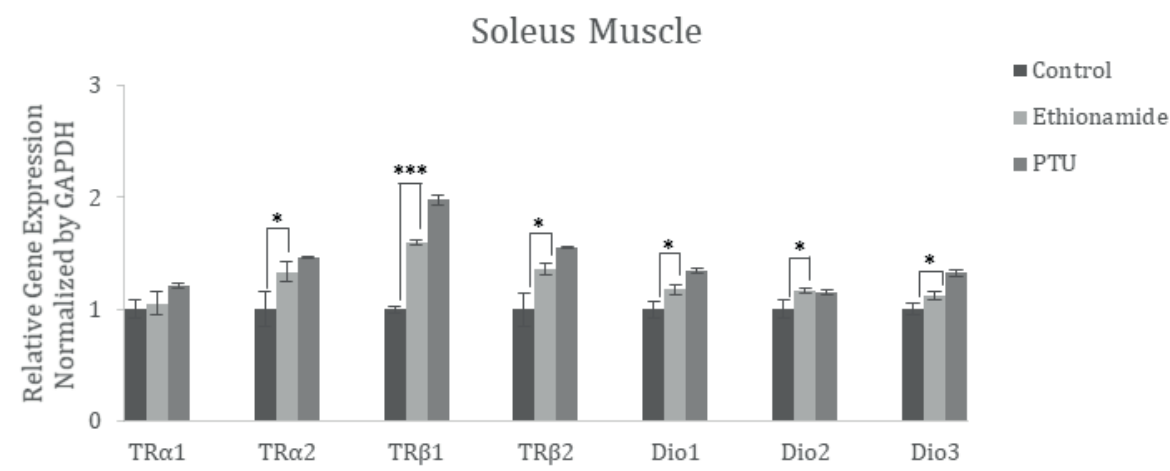

Figure 2. Relative gene expression level of TR $\alpha 1, T R \alpha 2, T R \beta 1, T R \beta 2$, Dio1, Dio2, and Dio3 in soleus muscle. Data were normalized with GAPDH and presented as relative ratio values (average mean $\pm \mathrm{SEM}$ ). ${ }^{*} p<0.05 ;{ }^{*} * p<0.001$ were considered as significant. Results were tested with One Way ANOVA test, Kruskal Wallis and followed by Mann Whitney or Tukey post hoc test with $95 \%$ confidence interval. 


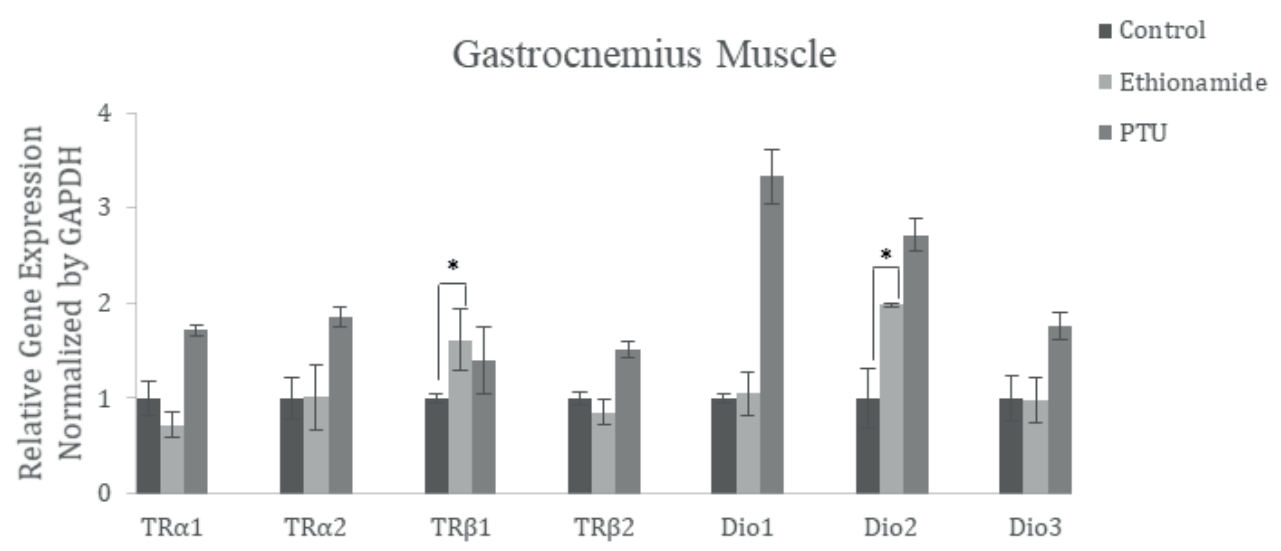

Figure 3. Relative gene expression level of TR $\alpha 1, T R \alpha 2, T R \beta 1, T R \beta 2, D i o 1, D i o 2$, and Dio3 in sastrocnemius muscle. Data were normalized with GAPDH and presented as relative ratio values (average mean $\pm \mathrm{SEM}$ ). ${ }^{*} p<0.05 ; * * * p<0.001$ were considered as significant. Results were tested with One Way ANOVA test, Kruskal Wallis and followed by Mann Whitney or Tukey post hoc test with $95 \%$ confidence interval.

complexes which will stimulate transcription. $(14,17)$ TR gene expression are expressed specifically in various organ, in this case is upregulating gene expression TR is expressed as different isoforms (TR $\alpha 1, T R \beta 1$, and $T R \beta 2$ ) differentially expressed in various tissues.(18)

In skeletal muscle, TR binds to thyroid response elements in genes regulated by thyroid hormones, forming heterodimers with the retinoid $\mathrm{X}$ receptor. Subsequent formation of a protein complex including NCoR2 corepressor and histone-modifying enzymes causes repression of transcription.(14,17) When T3 binds to the TR, repression is reduced and transcription is further stimulated by the recruitment of co-activators to the complex. Among proteins whose expression is regulated transcriptionally by $\mathrm{T} 3$ in muscle are sarco/endoplasmic reticulum $\mathrm{Ca}^{2+}$ ATPase (SERCA) 1a, SERCA2a, uncoupling protein (UCP)3, glucose transporter (GLUT)4, malic enzyme (ME)
1, mitochondrial glycerol 3-phosphate dehydrogenase (mGPDH), and myosin-7.(19-22) This is process that reflect a genomic regulation of thyroid hormone.

In soleus muscle, most of $\mathrm{TR}$ and iodothyronine deiondenase were significantly upregulated. Dio1, Dio2, and Dio3 which act as converting enzyme in thyroid hormoneskeletal muscle activation, were found significantly upregulated. TR $\alpha 2, T R \beta 1, T R \beta 2$ were also significantly upregulated. However, TRal was not upregulated significantly in soleus muscle (Figure 2). In gastrocnemius muscle, most of thyroid hormone receptor gene expression and iodothyronine deiodenase were not significantly upregulated. TRR1 and Dio2 were found significantly upregulated. On the contrary, TR $\alpha 1, T R \alpha 2, T R \beta 2$, Dio1, and Dio3 weren't significantly upregulated (Figure 3). The upregulation of TR and iodothyronine deiodenase gene expression may indicate compensation of hypothyroid

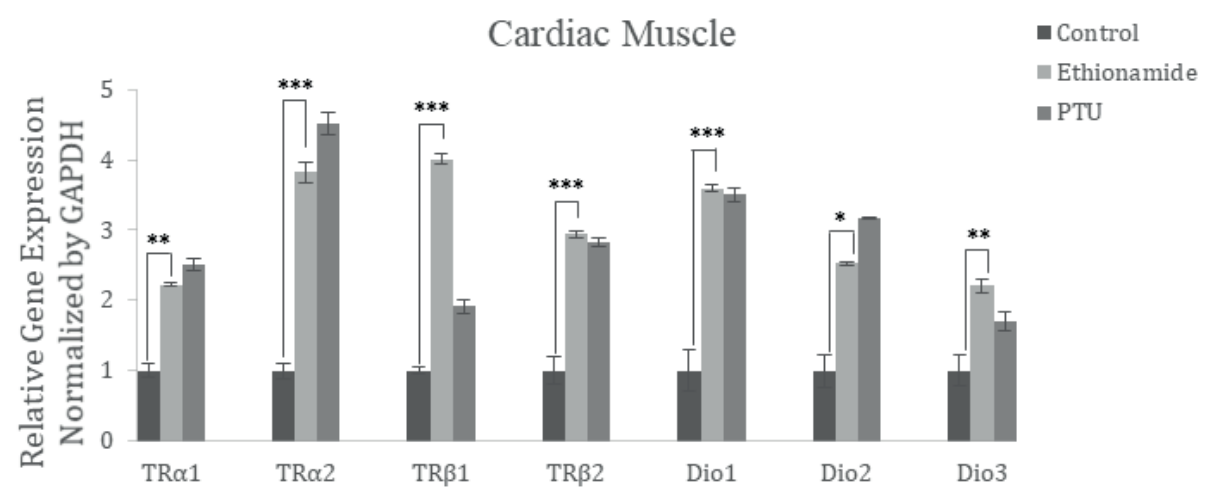

Figure 4. Relative gene expression level of TR $\alpha 1, T R \alpha 2, T R \beta 1, T R \beta 2$, Dio1, Dio2, and Dio3 in cardiac muscle. Data were normalized with GAPDH and presented as relative ratio values (average mean $\pm \mathrm{SEM}$ ). ${ }^{*} p<0.05$; ${ }^{* * *} p<0.001$ were considered as significant. Results were tested with One Way ANOVA test, Kruskal Wallis and followed by Mann Whitney or Tukey post hoc test with $95 \%$ confidence interval. 
environment in soleus and gastrocnemius muscle. Alteration of these mechanism may decrease contractility rate, growth, and metabolism of skeletal muscle. Thus, further research is still needed to understand the effects on tissue function.

Cardiac is one of the major target organ of $\mathrm{TH}$ action. T3, an active form of thyroid hormone binds to the TR in the same process as skeletal muscle, repression relieved and transcription is further stimulated by the recruitment of co-activators to the complex. TH in the cardiac muscle regulates the myosin heavy chain (MHC) genes which encode two contractile protein isoforms of the thick filament in cardiomyocyte. Triiodothyronine has positive effect on the transcription of the MHC $\alpha$ gene and negative effect on the MHC $\beta$ gene expression.(23-26) TH also regulates SERCA2a which is responsible for the calcium reuptake during the diastole, which important for systolic and diastolic function.(27-29) Understanding this important regulation of TH in cardiac muscle, our data had shown that TR $\alpha 1, T R \alpha 2, T R \beta 1, T R \beta 2$, Dio1, Dio2, and Dio3 were all significantly upregulated in cardiac muscle by ethionamide (Figure 4). Ethionamide could affect TRs signaling direct or indirectly. Level of thyroxine and triiodothyronine in serum might alter the TRs and iodothyronine deiodenase gene expression as compensation of hypothyroid environment in cardiac muscle. Alteration of these mechanism might decrease contractility, systolic, and diastolic function capability of the cardiac muscle.(30) However, further study is compulsory to understand the complete molecular mechanism on tissue function. TRs RNA expression could be altered by many external factor like exercise (31), medicine (32), environmental compounds like PCB (33), and also caused by internal factor like genetic mutation (34) The ethionamide might also alter the expression of Deiodinase gene expressions, this gene is important for activating enzyme and deactivating enzyme of $\mathrm{TH}$. Deiodinase 1, 2 and $3 \mathrm{mRNA}$ expression were significantly upregulated in soleus and cardiac muscle. In gastrocnemius muscle, only Dio2 was significantly upregulated (Figure 2-4) . Iodothyronine deiodinase 1 and 2 (Diol and Dio2) are activating enzyme which catalyze convertion of T4 into $\mathrm{T} 3$ in circulation, and iodothyronine deiodinase 3 (Dio3) act as deactivating enzyme which catalyze convertion of $\mathrm{T} 4$ into reverse T3 (rT3) and the conversion of T3 to T2. $(35,36)$ Different response and expression pattern might caused by different type of skeletal muscle fiber (red and white fibers). The alteration of TR gene expression in this research may lead to new perspective about thyroid hormone related study and tuberculosis treatment in the future. Although TR gene expression significantly upregulated in soleus muscle and cardiac muscle tissue, it is not confirmed whether it effects the function of the cells, hence needs to be further studied. However, specific alteration of TRs and Deiodinase gene expression might indicate that ethionamide could alter $\mathrm{TH}$ genomics signaling via modulating TRs expression. In the future, ethionamide treatment for MDR-TB patient should consider its side effect induce hypothyroidism. Alteration of these gene expression might still need further research to understand its mechanism on tissue function.

\section{Conclusion}

In summary, ethionamide significantly upregulate thyroid hormone receptor gene expression in soleus and cardiac muscle tissue but not in gastrocnemius muscle. The upregulation of TRS expression caused by ethionamide treatment should increase our awareness of ethionamide effect to TH signaling for TB treatment in the future.

\section{References}

1. Hallbauer UM, Schaaf HS. Ethionamide-induced hypothyroidism in children. South Afr J Epidemiol Infect. 2011; 26: 161-3.

2. Thee S, Garcia-Prats AJ, Donald PR, Hesseling AC, Schaaf HS. A review of the use of ethionamide and prothionamide in childhood tuberculosis. Tuberculosis. 2016; 97: 126-36.

3. Yang TW, Park HO, Jang HN, Yang JH, Kim SH, Moon SH, et al. Side effects associated with the treatment of multidrug-resistant tuberculosis at a tuberculosis referral hospital in South Korea Medicine. 2017; 96: e7482. doi: 10.1097/md.0000000000007482.

4. Thee S, Zöllner EW, Willemse M, Hesseling AC, Magdorf K, Schaaf HS. Abnormal thyroid function tests in children on ethionamide treatment. Int J Tuberc Lung Dis. 2011; 15: 1191-3.

5. Joseph P, Desai VBR, Mohan NS, Fredrick JS, Ramachandran R, Raman B, et al. Outcome of standardized treatment for patients with MDR-TB from Tamil Nadu, India. Indian J Med Res. 2011; 133: 529-34.

6. Modongo C, Zetola NM. Prevalence of hypothyroidism among MDR-TB patients in Botswana. Int J Tuberc Lung Dis. 2012. 16 : 1561-2.

7. Mallela AR, Koya R, Nagari SK, Mohapatra AK. Ethionamide: Unusual cause of hypothyroidism. J Clin Diagn Res. 2015; 9: OD08-9. doi: 10.7860/JCDR/2015/13531.6331.

8. Braverman LE, Cooper DS, Kopp PA, Ingbar SH. Werner \& Ingbar's The Thyroid : A Fundamental and Clinical Text. Philadelphia: Wolters Kluwer Health/Lippincott Williams \& Wilkins; 2013.

9. Cheng SY, Leonard JL, Davis PJ. Molecular aspects of thyroid hormone actions. Endocr Rev. 2010; 31: 139-70.

10. Oetting A, Yen PM. New insights into thyroid hormone action. Best Pract Res Clin Endocrinol Metab. 2007; 21: 193-208.

11. Sperling M. Pediatric Endocrinology. $4^{\text {th }}$ Edition. Philadelphia: Saunders; 2014.

12. McDonnell ME, Braverman LE, Bernardo J. Hypothyroidism due to ethionamide. N Engl J Med. 2005; 352: 2757-9. 
13. Baquedano MS, Ciaccio M, Dujovne N, Herzovich V, Longueira Y, Warman DM, et al. Two novel mutations of the TSH-beta subunit gene underlying congenital central hypothyroidism undetectable in neonatal TSH screening. J Clin Endocrinol Metab. 2010; 95: E98103.

14. Ortiga-Carvalho TM, Chiamolera MI, Pazos-Moura CC, Wondisford FE. Hypothalamus-pituitary-thyroid axis. Compr Physiol. 2016; 6: 1387-428.

15. Lefebvre P, Benomar Y, Staels B. Retinoid X receptors: common heterodimerization partners with distinct functions. Trends Endocrinol Metab. 2010; 21: 676-83.

16. Calsolaro V, Niccolai F, Pasqualetti G, Calabrese AM, Polini A, Okoye $\mathrm{C}$, et al. Overt and subclinical hypothyroidism in the elderly: when to treat? Front Endocrinol. 2019; 10: 177. doi: 10.3389/ fendo.2019.00177.

17. Brent GA. Mechanisms of thyroid hormone action. J Clin Invest. 2012; 122: 3035-43.

18. Yen PM, Darling DS, Chin WW. Basal and thyroid hormone receptor auxiliary protein-enhanced binding of thyroid hormone receptor isoforms to native thyroid hormone response elements. Endocrinology. 1991; 129: 3331-6.

19. Simonides WS, van Hardeveld C. Thyroid hormone as a determinant of metabolic and contractile phenotype of skeletal muscle. Thyroid. 2008; 18(2): 205-16.

20. Solanes G, Pedraza N, Calvo V, Vidal-Puig A, Lowell Bb, Villarroya F. Thyroid hormones directly activate the expression of the human and mouse uncoupling protein-3 genes through a thyroid response element in the proximal promoter region. Biochem J. 2005; 386: 505-13.

21. Zorzano A, Palacin M, Guma A. Mechanisms regulating GLUT4 glucose transporter expression and glucose transport in skeletal muscle. Acta Physiol Scand. 2005; 183: 43-58.

22. Dillmann W. Cardiac hypertrophy and thyroid hormone signaling. Heart Fail Rev. 2010; 15: 125-32.

23. Kahaly GJ, Dillmann WHJER. Thyroid hormone action in the heart. Endocr Rev. 2005; 26: 704-28.

24. Yen PM, Ando S, Feng X, Liu Y, Maruvada P, Xia X. Thyroid hormone action at the cellular, genomic and target gene levels. Mol Cell Endocrinol. 2006; 246: 121-7.
25. Kuzman J, Gerdes A, Kobayashi S, Liang Q. Thyroid hormone activates Akt and prevents serum starvation-induced cell death in neonatal rat cardiomyocytes. J Mol Cell Cardiol. 2005; 39: 841-4.

26. Kenessey A, Ojamaa K. Thyroid hormone stimulates protein synthesis in the cardiomyocyte by activating the Akt-mTOR and p70S6K pathways. J Biol Chem. 2006; 281: 20666-72.

27. Ito K, Kagaya Y, Shimokawa H. Thyroid hormone and chronically unloaded hearts. Vascul Pharmacol. 2010; 52: 138-41.

28. Stammers AN, Susser SE, Hamm NC, Hlynsky MW, Kimber DE, Kehler DS, et al. The regulation of sarco (endo) plasmic reticulum calcium-ATPases (SERCA). Can J Physiol Pharm. 2015; 93: 84354.

29. Davis PJ, Leonard JL, Davis FB. Mechanisms of nongenomic actions of thyroid hormone. Front Neuroendocrinol. 2008; 29: 211-8.

30. Grais IM, Sowers JR. Thyroid and the heart. Am J Med. 2014; 127 : 691-8.

31. Lesmana R, Iwasaki T, Iizuka Y, Amano I, Shimokawa N, Koibuchi $\mathrm{N}$. The change in thyroid hormone signaling by altered training intensity in male rat skeletal muscle. Endocr J. 2016; 63: 727-38.

32. Schapira M, Raaka BM, Das S, Fan L, Totrov M, Zhou Z, et al. Discovery of diverse thyroid hormone receptor antagonists by high-throughput docking. Proc Natl Acad Sci USA. 2003; 100: 7354-9.

33. Miyazaki W, Iwasaki T, Takeshita A, Kuroda Y, Koibuchi N Polychlorinated biphenyls suppress thyroid hormone receptormediated transcription through a novel mechanism. J Biol Chem. 2004; 279: 18195-202.

34. Machado DS, Sabet A, Santiago LA, Sidhaye AR, Chiamolera MI, Ortiga-Carvalho TM, et al. A thyroid hormone receptor mutation that dissociates thyroid hormone regulation of gene expression in vivo. Proc Natl Acad Sci USA. 2009; 106: p. 9441-6.

35. Estivalet AAF, Leiria LB, Dora JM, Rheinheimer J, Bouças AP, Maia AL, et al. D2 Thr92Ala and PPARgamma2 Pro12Ala polymorphisms interact in the modulation of insulin resistance in type 2 diabetic patients. Obesity. 2011; 19: 825-32.

36. Mentuccia D, Thomas MJ, Coppotelli G, Reinhart LJ, Mitchell BD, Shuldiner AR, et al. The Thr92Ala deiodinase type 2 (DIO2) variant is not associated with type 2 diabetes or indices of insulin resistance in the old order of Amish. Thyroid. 2005; 15: 1223-7. 